\title{
Fibroepithelial polyp of the urinary bladder
}

\author{
Powała Agnieszka, Kuzaka Bolesław, Hanecki Ryszard, Ewa Skrzypek, Górnicka Barbara, \\ Radziszewski Piotr
}

Department of Histopathology and Department of General Oncological and Functional Urology, Medical University, Warsaw, Poland

Correspondence: Bolesław Kuzaka. Address: Department of General Oncological and Functional Urology, Medical University, Poland. Email: boleslaw.kuzaka@wum.edu.pl

Received: November 16, 2014

Accepted: January 1, $2015 \quad$ Online Published: February 7, 2015

DOI: $10.5430 /$ jst.v5n1p23

URL: http://dx.doi.org/10.5430/jst.v5n1p23

\section{Abstract}

Nonneoplastic polyps in the urinary bladder are benign mucosal lesions which occur rarely, usually in young to middle-aged adults. Fibroepithelial polyps of the bladder are occasionally able to epithelial pseudocarcinomatous multiply. We report a case of a polypoid tumor with epithelial proliferation in the urinary bladder in a young man treated in the Department of General, Oncological and Functional Urology, Medical University of Warsaw. The tumor was resected and found to be a fibroepithelial polyp.

\section{Key words}

Fibroepithelial polyp, Urinary bladder, Transurethral resection

\section{Introduction}

Fibroepithelial polyps of the urinary tract are benign mucosal lesions which occur rarely, usually in young to middle-aged adults, but can also occur in children and the elderly, with a higher frequency in males. The etiology of most fibroepithelial polyps is obscure, but many are considered to be either of congenital or inflammatory origin and are often associated with calculi. Polyps occur most commonly in the renal pelvis, proximal ureter, also near verumontanum, ureteropelvic junction or bladder $^{[1,2]}$.

\section{Case report}

A 29-year-old man patient presented in the Department of General, Oncological and Functional Urology, Medical University of Warsaw complaining of painless macroscopic hematuria of four-month duration. The patient did not report previous urinary tract disorders and/or use of drugs. CT-scan and cystosocopy identified the presence of an exophytic papillary "non-typical" tumor on the anterior wall of the bladder, of a $7 \mathrm{~mm} \times 6 \mathrm{~mm}$ dimension. The lesion was removed transurethrally with broad margins. The base was coagulated. There were no other lesions in the bladder.

Morphologically, the tumor consists of protruded foldings with dense fibrous core lined by columnar epithelium. The polyp exhibited a striking epithelial proliferation with florid glands in the stalk. The densely distributed glands seemed to resemble a neoplastic infiltration lesion. Figure 1, but the cytological picture of the epithelial cells of the glands did not 
reveal either atypia or mitoses. The lesion lacked prominent edema and inflammation (see Figures 2 and 3). The additionally collected specimen of the base, including the muscular wall, revealed no changes. The postoperative period was uneventful. After three month the patient had a follow - up cystoscopy. Repeated (Transurethral resection of tumor) TURT showed a cicatritial alteration with a surface crust. Microscopically, scant inflammatory infiltration with fibrosis in the subepithelial layer was found. A half-year follow-up was secured and ultrasonography showed a bladder without any alternations.

Figure 1. The densely distributed glands seem to resemble a neoplastic infiltration at magnification $10 \times$

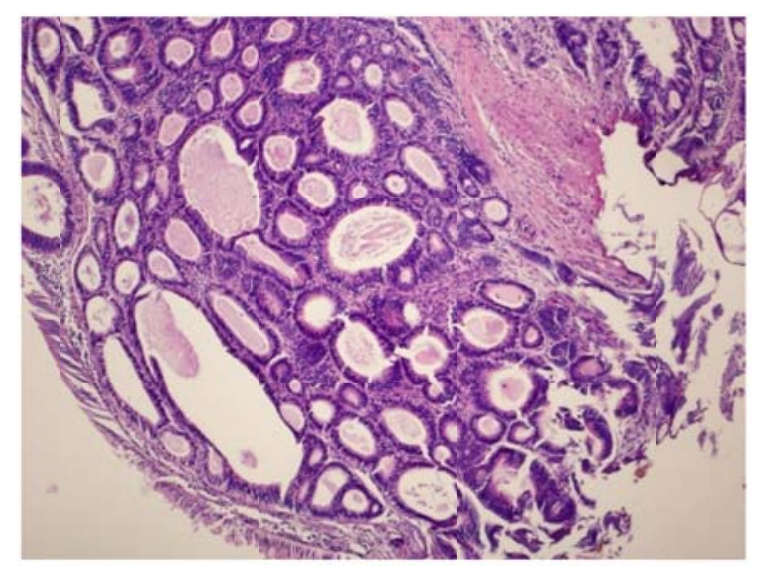

However a magnification $20 \times$ and $40 \times$ (see Figures 2 and 3) shows bland cytology of the epithelium and a fibrous stroma without a desmoplasia.

Figure 2. Bland cytology of the epithet-lium and a fibrous stroma without a desmoplasia, magnification $20 \times$

Figure 3. Bland cytology of the epithelium and a fibrous stroma without a desmoplasia, magnification $40 \times$
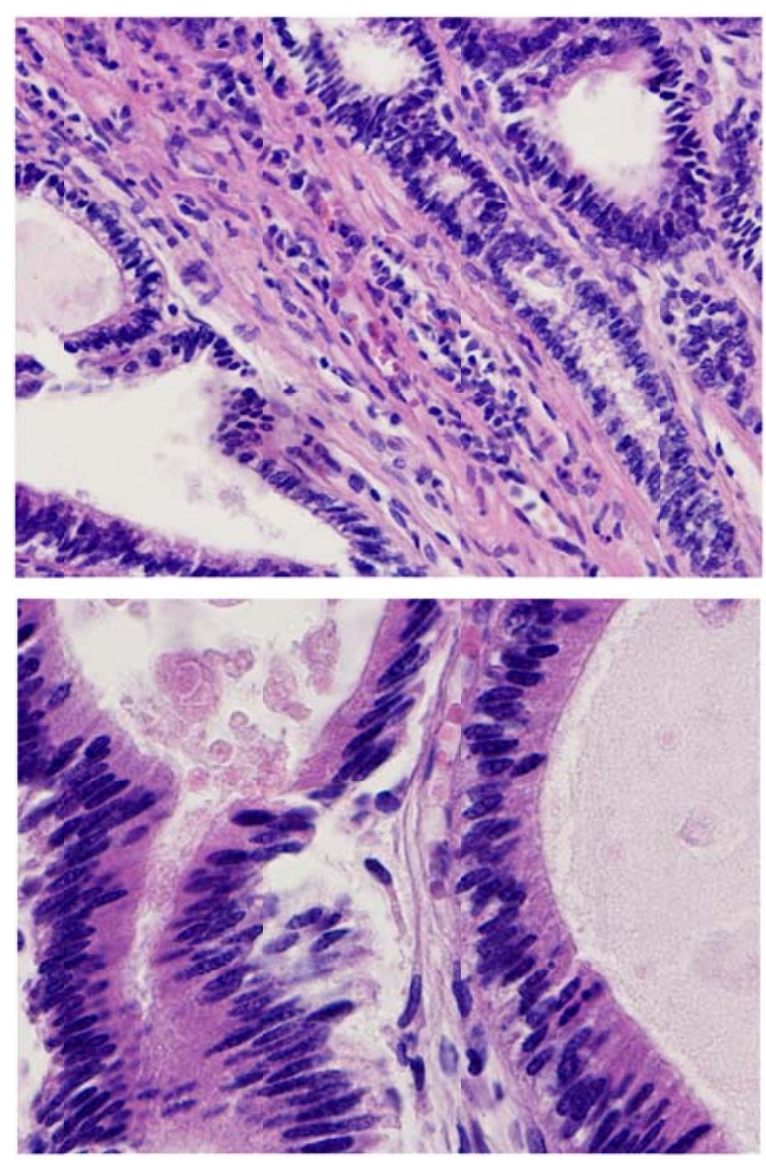


\section{Discussion}

Tumor-like lesions of the urinary bladder are diagnostically most challenging for the pathologist and may result in serious errors in patient care if misinterpreted. Histologically, all of the fibroepithelial polyps are lined by normal-appearing urothelium, or columnar epithelium. Literature revealed three types of fibroepithelial polyps. The one of them consists of a fibrous structure, which are more distinct due to a more prominent component, with areas resemble cystitis cystica. The second form is built of many small fibrovascular cores covered with bland cytology of the epithelium. The last type consist of a big stalk with a prominent epithelial proliferation in the stroma. The fibroepithelial polyp may be confused with glandular carcinoma, if exhibit dense, crowd proliferation of glands ${ }^{[3]}$. Regarding our patient we had to correlated histological view to the clinical picture of the lesion. That is the only way to make the proper diagnosis. The lesion appears "strange" on cystoscopy. Histologically, the polyp should be differentiated from adenocarcinoma of the bladder, cystitis cystic or if it located on the anterior wall of the bladder, from urachal adenocarcinoma. A correct diagnosis allows the choice of the most adequate surgical management. In invasive adenocarcinoma of the bladder significant atypia or mitoses are seen. Glandular nests in fibroepithelial polyp may by identical to cystitis cystica, and glandularis, in contrast there is no exophytic papillary component and the intervening stroma characterize with oedema and inflammation ${ }^{[4]}$. Urachal adenocarcinomais characterized by infiltration muscularis propria through mucinus adenocarcinoma ${ }^{[5]}$.

Infrequently there are reccurence after resection of fibroepithelial polyp, but the malignant transformation haven't occurred earlier. The relapses mostly appear because of non-radical resection. They are not caused by malignant transformation ${ }^{[6,7]}$. The best tool to observe the patients after treatment remains ultrasound examination and in special cases magnetic resonance imaging (MRI).

\section{References}

[1] Kojima Y, Lambert SM, Steixner BL, et al. Multiple metachronousfibroepithelial polyps in children. J Urol. 2011 ; $185: 1053$. PMid:21256525 http://dx.doi.org/10.1016/j.juro.2010.10.046

[2] Bolton B, Stoller ML, Irby P. Fibroepithelial ureteral polyps and urolithiasis. Urology. 1994; 44: 582. http://dx.doi.org/10.1016/S0090-4295(94)80066-9

[3] Young RH. Tumor-likelesions of the urinary bladder. Mod Pathol. 2009; Jun 22 Suppl 2S: 37-52. PMid:19494852 http://dx.doi.org/10.1038/modpathol.2008.201

[4] Toyonori T, Epstein J. Fibroepithelial polyp of the lower urinary tract in adults. Am J Surg Pathol. 2005; 29(4): 460-466. http://dx.doi.org/10.1097/01.pas.0000155153.64360.1a

[5] Singh I, Prasad R. Primary urachalmucinous adenocarcinoma of the urinary bladder. J Clin Diagn Res. 2013 May; 7(5): 911-3. PMid:23814741

[6] Tsuzuki T, Epstein JI. Fibroepithelial polyp of the lower urinary tract in adults. Am J Surg Pathol. 2005; 29 : $460-466$. http://dx.doi.org/10.1097/01.pas.0000155153.64360.1a

[7] Ruíz-López MJ, Ramírez-Garrido F, Nogueras-Ocaña M, et al. Recurrent ureteric fibroepithelial polyp in a child. Eur J Pediatr. 2004; 163(2): 124-5. PMid:14716557 http://dx.doi.org/10.1007/s00431-002-1052-3 